\title{
Production and purification of hydrogen by biogas combined reforming and steam-iron process
}

\author{
J. Lachén, J. Herguido, J.A. Peña* \\ Aragon Institute of Engineering Research (I3A), Universidad Zaragoza, Mariano Esquillor, 3; Ed. "I+D”, E50018 \\ Zaragoza, Spain
}

\section{A R T I C L E I N F O}

Article history:

Received 30 November 2017

Received in revised form

13 April 2018

Accepted 18 April 2018

Available online $\mathrm{xxx}$

\section{Keywords:}

Biogas

Combined reforming

Chemical looping

Catalysis

Steam-iron process

\begin{abstract}
A B S T R A C T
Cobalt ferrite and hematite with minor additives have been tested for production and purification of high purity hydrogen from a synthetic biogas by steam-iron process (SIP) in a fixed bed reactor. A catalyst based in nickel aluminate has been included in the bed of solids to enhance the rate of the reaction of methane dry reforming (MDR). The reductants resulting from MDR are responsible for reducing the oxides based on iron that will, in the following stage, be oxidized by steam to release hydrogen with less than $50 \mathrm{ppm}$ of CO. Coke minimization along reduction stages forces to operate such reactors above $700{ }^{\circ} \mathrm{C}$ for reductions, and as low as $500{ }^{\circ} \mathrm{C}$ for oxidations to avoid coke gasification. To avoid problems such as reactor clogging by coke in reductions and/or contamination of hydrogen by gasification of coke along oxidations, steam in small proportions has been included in the feed with the aim of minimizing or even avoiding formation of carbonaceous depositions along the reduction stage of SIP. Since steam is an oxidant, it exerts an inhibiting effect upon reduction of the oxide, that slows down the efficiency of the process. It has been proved that co-feeding low proportions of steam with an equimolar mixture of $\mathrm{CH}_{4}$ and $\mathrm{CO}_{2}$ (simulating a poor heating value desulphurized biogas) is able to avoid coke deposition, allowing the operation of both, reductions and oxidations, in isothermal regime $\left(700{ }^{\circ} \mathrm{C}\right)$. Empirical results have been contrasted with data found in literature for similar processes based in MDR and combined (or mixed) reforming process (CMR), concluding that the combination of MDR + SIP proposed in this work, taking apart economic aspects and complex engineering, shows similar yields towards hydrogen, but with the advantage of not requiring a subsequent purification process.
\end{abstract}

๑ 2018 Hydrogen Energy Publications LLC. Published by Elsevier Ltd. All rights reserved.

\section{Introduction}

The main environmental problem nowadays, the climate change, is attributed to the emissions of greenhouse gases derived from the exploitation of fossil fuels. To mitigate it at least partially, it is necessary to introduce environmental friendly alternatives to these raw materials. Mobility is one of the niches where reducing the use of fossil fuels could make a greater impact in the release of $\mathrm{CO}_{2}$ to the atmosphere. In this context, hydrogen is called to be the path leading to the solution through the use of fuel cell powered vehicles (PEMFC) [1]. However, since this resource cannot be found isolated in nature, the first step begins with its production from several

\footnotetext{
* Corresponding author.

E-mail address: jap@unizar.es (J.A. Peña).
} 
sources. Although serious research efforts have been directed in the last decades, both from academia and industry, to enhance the processes based on electrolysis with surplus electricity, most part of hydrogen produced today still comes from steam reforming of natural gas and/or coal [2]. A suitable way to cope with the problem of greenhouse gases emission, which come from the still significant reserves of fossil fuels like natural gas or coal, might consist of taking advantage of big scale production centers where capture and storage methods of $\mathrm{CO}_{2}$ are efficiently applied. The main problem is that processing exhaust gases by absorption methods with chemicals (e.g. monoethanolamine -MEA-), results in a significant increment in the process costs [3]. Other promising processes, like those based on $\mathrm{CO}_{2}$ capture technologies such as chemical looping combustion (CLC) [4], are still under development. In this framework, it is proposed the use of biogas, produced in bio-digesters by anaerobic fermentation of organic matter as a raw material (municipal solid waste, sewage sludge, forestry, agricultural, cattle or food industry wastes to name the most relevant), to produce hydrogen. This strategy combines the suitable exploitation of enormous amounts of feedstock today scarcely processed, to produce bio-hydrogen which connects with the concept of circular economy [5]: use of wastes to cover energy demands.

In spite of the traditional reforming processes, this work is devoted to produce and purify hydrogen from biogas by a combined technique of methane dry reforming (MDR) and steam iron process (SIP) [6]. This method is closely related to the above mentioned CLC. It is based, as this last, in the redox properties of metal oxides: In a first stage, the products resulting from the methane dry reforming of a biogas (MDR) reduce the metal oxide to a lower oxidation state (r.1a and r.1b). Later, in a subsequent stage, the metal can be reoxidized with steam (r.2), releasing hydrogen easily separable from unreacted steam by condensation.

$\mathrm{Fe}_{2} \mathrm{O}_{3}+3 \mathrm{H}_{2} \rightleftharpoons 2 \mathrm{Fe}+3 \mathrm{H}_{2} \mathrm{O}$

$\mathrm{Fe}_{2} \mathrm{O}_{3}+3 \mathrm{CO} \rightleftharpoons 2 \mathrm{Fe}+3 \mathrm{CO}_{2}$

$3 \mathrm{Fe}+4 \mathrm{H}_{2} \mathrm{O} \rightleftharpoons \mathrm{Fe}_{3} \mathrm{O}_{4}+4 \mathrm{H}_{2}$

The use of biogas as source of reducing species has been previously tested in other works of our research group [7-10]. Same approach has been followed with other renewable raw materials like bio-oil [11-13] using both, synthetic oxides and natural metal ores. Given the poor catalytic activity of the oxygen carriers used in this work [7,9], it has been required improving the activity of the bed of solids for MDR by adding a nickel aluminate catalyst.

Perhaps one of the main drawbacks regarding this process is the loss of reactivity that the oxygen carrier suffers along redox cycles, partially due to the crystalline structure of the solid and the high temperatures required for MDR and reduction of the solid. Keeping this in mind, and in order to maximize the production of hydrogen, a moderate temperature $\left(700^{\circ} \mathrm{C}\right)$ has been used for reduction stages based on our previous experience $[7,8,10]$. However, under these conditions, the accumulation of carbonaceous deposits on the bed of solids becomes a serious drawback. If not removed, coke could cause reactor clogging. On the other hand, coke deposition along reductions exerts a severe restriction in the subsequent oxidation stages, limiting seriously the allowed range of temperatures to be employed: oxidation temperatures should be low enough to avoid gasification of carbon residues by steam, releasing $\mathrm{CO}_{\mathrm{x}}$ that would contaminate the high purity $\mathrm{H}_{2}$ stream resulting from the joint process.

For that reason, it is proposed the concept of co-feeding low proportions of steam along with biogas in the reduction stage, to avoid or at least minimize, the formation of carbon deposits that would make the purification of hydrogen unpractical. Basically, it means that a combined reforming process (dry + steam reforming -MDR + MSR-) along with redox reactions (SIP) is going to be explored. This solution has been applied similarly in other dry reforming processes [14-17]. In these projects, the addition of different percentages of water allowed to regulate the $\mathrm{H}_{2}$ : $\mathrm{CO}$ ratio of the synthesis gas, being interesting for producing long chain hydrocarbons via FischerTropsch reaction [14]. However, since the objective in SIP is reducing a metal oxide, co-feeding an oxidant such as steam, could inhibit or at least slow down the reduction reactions. Concluding, in this work it will be analyzed the technical feasibility of this alternative as solution to prevent reactor clogging. Also, hydrogen yields will be compared with data of similar processes found in literature.

\section{Experimental}

\section{Solids}

Two different oxygen carriers have been selected in the present work: hematite doped with low proportions of alumina and ceria, (98 wt\% $\mathrm{Fe}_{2} \mathrm{O}_{3}, 1.75 \mathrm{wt} \% \mathrm{Al}_{2} \mathrm{O}_{3}$ and $0.25 \mathrm{wt} \% \mathrm{CeO}_{2}$ ) colloquially called "triple" oxide, and cobalt ferrite with added alumina which acts as stabilizer of the structure, with stoichiometric formula $\mathrm{Al}_{0.53} \mathrm{Co}_{0.8} \mathrm{Fe}_{1.6} \mathrm{O}_{4}$.

The first solid has been synthesized in laboratory by the citrates method [18]. Essentially, the synthesis method consists of the preparation of a $1 \mathrm{M}$ solution from the corresponding metal nitrate salts under stirring at $70^{\circ} \mathrm{C}$. Once a gel is formed, after about $3 \mathrm{~h}$, it was dried overnight and calcined in a double ramp, first up to $350^{\circ} \mathrm{C}$ along $2.5 \mathrm{~h}$ and later up to $850{ }^{\circ} \mathrm{C}$ along $8 \mathrm{~h}$.

Cobalt ferrite was synthesized by co-fusion [19]. Once the corresponding nitrate salts of each of the metals have been weighed and mixed, they were calcined for $6 \mathrm{~h}$ at $1000^{\circ} \mathrm{C}$.

The catalyst was composed of a nickel aluminate with $10 \mathrm{wt} \%$ excess of nickel oxide above its stoichiometric composition. This composition was synthesized by coprecipitation at increasing $\mathrm{pH}$ [20], and optimized in a previous work [9]. Firstly, solutions of aluminum nitrate and nickel nitrate, $1 \mathrm{M}$ and $0.631 \mathrm{M}$ respectively, were prepared and then mixed. An aqueous solution of $\mathrm{NH}_{4} \mathrm{OH}$ (30 wt\%) was added with continuous stirring at $45^{\circ} \mathrm{C}$ to obtain the solution at $\mathrm{pH}$ 7.8-7.9. Then it was filtered, washed and dried overnight at $100{ }^{\circ} \mathrm{C}$. Finally, it was calcined at $900^{\circ} \mathrm{C}$ for $3 \mathrm{~h}$.

All solids, both oxygen carriers and catalyst, were ground and sieved up to obtain a particle size between 100 and $200 \mu \mathrm{m}$. 


\section{Experimental setup}

Tests were carried out in a fixed bed reactor made of quartz $\left(\varnothing_{\mathrm{i}}=0.013 \mathrm{~m}\right)$. The bed was constituted by $2.5 \mathrm{~g}$ of solid composed of $67.5 \mathrm{wt} \%$ of oxygen carrier, $7.5 \mathrm{wt} \%$ of catalyst and $25 \mathrm{wt} \%$ of silicon carbide (same size as oxygen carriers and catalyst) as an inert solid.

Each cycle consisted of two steps: First, the reduction of the bed of solids by feeding a mixture simulating a desulphurized biogas (reduction step) up to achieving a steady behaviour. The length of reduction steps, once determined, was kept for all cycles at given operating conditions. This was followed by an inertization period with argon. Finally, the previously reduced metal was reoxidized with steam for $60 \mathrm{~min}$ to release high purity hydrogen (oxidation step). After a new inertization period followed a new cycle of alternating reductions, inertizations and oxidations.

Reduction stages were performed at $700{ }^{\circ} \mathrm{C}$ supplying $250 \mathrm{~mL}$ (STP)/min as total flow, composed of $25 \mathrm{v} \%$ of an equimolar $\mathrm{CH}_{4}: \mathrm{CO}_{2}$ mixture (simulating a previously desulphurized biogas with low methane content), between 0 and 20 $\mathrm{v} \%$ of steam, $5 \mathrm{v} \%$ of $\mathrm{N}_{2}$ as internal standard and Ar to balance.

Oxidation stages were performed in a temperature range between 500 and $700{ }^{\circ} \mathrm{C}$, feeding total flows equivalent to those used in the reduction stage. In these cases, though, they were composed of $25 \mathrm{v} \%$ steam, $5 \mathrm{v} \%$ of $\mathrm{N}_{2}$ as internal standard and Ar to balance.

Water supply was performed using an HPLC pump (Shimadzu LC-20AT), that was vaporized up to the reaction temperature before feeding the reactor. Exhaust gases were continuously analyzed by a $\mu$-GC (Agilent 490) with Molisieve $5 \AA$ and PoraPlot $\mathrm{Q}$ columns. Water at the exit of the reactor was always forced to condense with the aid of a Peltier module (cold trap) to preserve the integrity of the $\mu$-GC.

Detailed topology of the conceptual process described in the paragraphs above, as well as a comparison of the economics in different scenarios, can be consulted in a recent work of the same research group [21].

\section{Results and discussion}

\section{Standard experiment: reduction and oxidation stages}

When steam is fed jointly with biogas, the main reactions that take place along the reduction stage in the gas phase are Methane Dry Reforming -MDR- (r.3) and Methane Steam Reforming -MSR- (r.4), as well as parallel and/or series reactions resulting from the interaction between reactants and gaseous products such as Water Gas Shift -WGS- reaction (r.5), and Boudouard equilibrium (r.6).

$\mathrm{CH}_{4}+\mathrm{CO}_{2} \rightarrow 2 \mathrm{H}_{2}+2 \mathrm{CO}$

$\mathrm{CH}_{4}+\mathrm{H}_{2} \mathrm{O} \rightarrow 3 \mathrm{H}_{2}+\mathrm{CO}$

$\mathrm{CO}+\mathrm{H}_{2} \mathrm{O} \rightleftharpoons \mathrm{CO}_{2}+\mathrm{H}_{2}$

$2 \mathrm{CO} \rightleftharpoons \mathrm{CO}_{2}+\mathrm{C}$
Moreover, also gas-solid reactions take place along the reduction stage: the in-situ activation of the catalyst by consumption of lattice oxygen of nickel oxide by methane (r.7), and in case of cobalt ferrites as oxygen carrier, its reduction by consumption of methane present in the biogas supplied (r.8) and/or hydrogen (r.9) or carbon monoxide (r.10) produced by the reactions (r.3) and (r.4).

$$
\begin{aligned}
& 4 \mathrm{NiO}+\mathrm{CH}_{4} \rightarrow 4 \mathrm{Ni}+\mathrm{CO}_{2}+2 \mathrm{H}_{2} \mathrm{O} \\
& \mathrm{CoFe}_{2} \mathrm{O}_{4}+\mathrm{CH}_{4} \rightleftharpoons \mathrm{Co}+2 \mathrm{Fe}+\mathrm{CO}_{2}+2 \mathrm{H}_{2} \mathrm{O} \\
& \mathrm{CoFe}_{2} \mathrm{O}_{4}+\mathrm{H}_{2} \rightleftharpoons \mathrm{Co}+2 \mathrm{Fe}+\mathrm{H}_{2} \mathrm{O} \\
& \mathrm{CoFe}_{2} \mathrm{O}_{4}+\mathrm{CO} \rightleftharpoons \mathrm{Co}+2 \mathrm{Fe}+\mathrm{CO}_{2}
\end{aligned}
$$

In case of triple oxide, the reaction mechanism is slightly different, because it is influenced by the different oxidation stages of the iron oxide up to metallic iron (hematite $\rightarrow$ magnetite $\rightarrow$ wustite $\rightarrow$ iron). Methane supplied in the feed, and hydrogen and carbon monoxide formed from (r.3) and (r.4) will allow the reduction of hematite to magnetite (r.11), (r.12), (r.13). Finally, and unlike with cobalt ferrites, only hydrogen and carbon monoxide will allow the reduction of magnetite to metallic iron as described by (r.14) and (r.15).

$$
\begin{aligned}
& 12 \mathrm{Fe}_{2} \mathrm{O}_{3}+\mathrm{CH}_{4} \rightarrow 8 \mathrm{Fe}_{3} \mathrm{O}_{4}+\mathrm{CO}_{2}+2 \mathrm{H}_{2} \mathrm{O} \\
& 3 \mathrm{Fe}_{2} \mathrm{O}_{3}+\mathrm{H}_{2} \rightarrow 2 \mathrm{Fe}_{3} \mathrm{O}_{4}+\mathrm{H}_{2} \mathrm{O} \\
& 3 \mathrm{Fe}_{2} \mathrm{O}_{3}+\mathrm{CO} \rightarrow 2 \mathrm{Fe}_{3} \mathrm{O}_{4}+\mathrm{CO}_{2} \\
& \mathrm{Fe}_{3} \mathrm{O}_{4}+4 \mathrm{H}_{2} \rightleftharpoons 3 \mathrm{Fe}+4 \mathrm{H}_{2} \mathrm{O} \\
& \mathrm{Fe}_{3} \mathrm{O}_{4}+4 \mathrm{CO} \rightleftharpoons 3 \mathrm{Fe}+4 \mathrm{CO}_{2}
\end{aligned}
$$

Fig. 1 shows the experiment considered as reference for triple oxide (Fig. 1a) and cobalt ferrite (Fig. 1b). It was carried out, regardless of the oxygen carrier tested, at $700{ }^{\circ} \mathrm{C}$ and with a $\mathrm{CH}_{4}: \mathrm{CO}_{2}$ ratio of 1 accounting for $25 \mathrm{v} \%$ of the total mixture, and including $5 \mathrm{v} \%$ of steam, $5 \mathrm{v} \%$ of nitrogen as internal standard and argon to complete the balance. As can be observed for both solids, the reduction stage has been divided, for the sake of explanation in two steps (A and $B$ ), according to its behaviour. The first one (A), describes the reduction of the oxide. Along step $B$ the oxygen from the former oxide has been completely depleted leaving only the reduced metal. The distribution of molar flows is determined by the thermodynamic equilibrium among gaseous species, that can be predicted by minimization of the Gibbs free energy.

Singularities arise for each one of the solids tested: In case of triple oxide (Fig. 1a), period A can be divided into two substeps $\left(A_{1}\right.$ and $\left.A_{2}\right)$. In $A_{1}$, the appearance of metallic nickel (r.7) favours the MDR reaction (r.3) because of its catalytic effect. At the beginning, it can be observed an almost complete absence of $\mathrm{H}_{2}$ and $\mathrm{CO}$, (products of MDR) which are being consumed in-situ by the solid, while other gaseous species coming from the reduction of the oxide $\left(\mathrm{CO}_{2}\right.$ and $\mathrm{H}_{2} \mathrm{O}$-not shown for the sake of clarity-), present higher flows than those fed. Also in this sub-step $A_{1}$, it can be confirmed the reduction of hematite to magnetite ((r.11), (r.12) and (r.13)). 


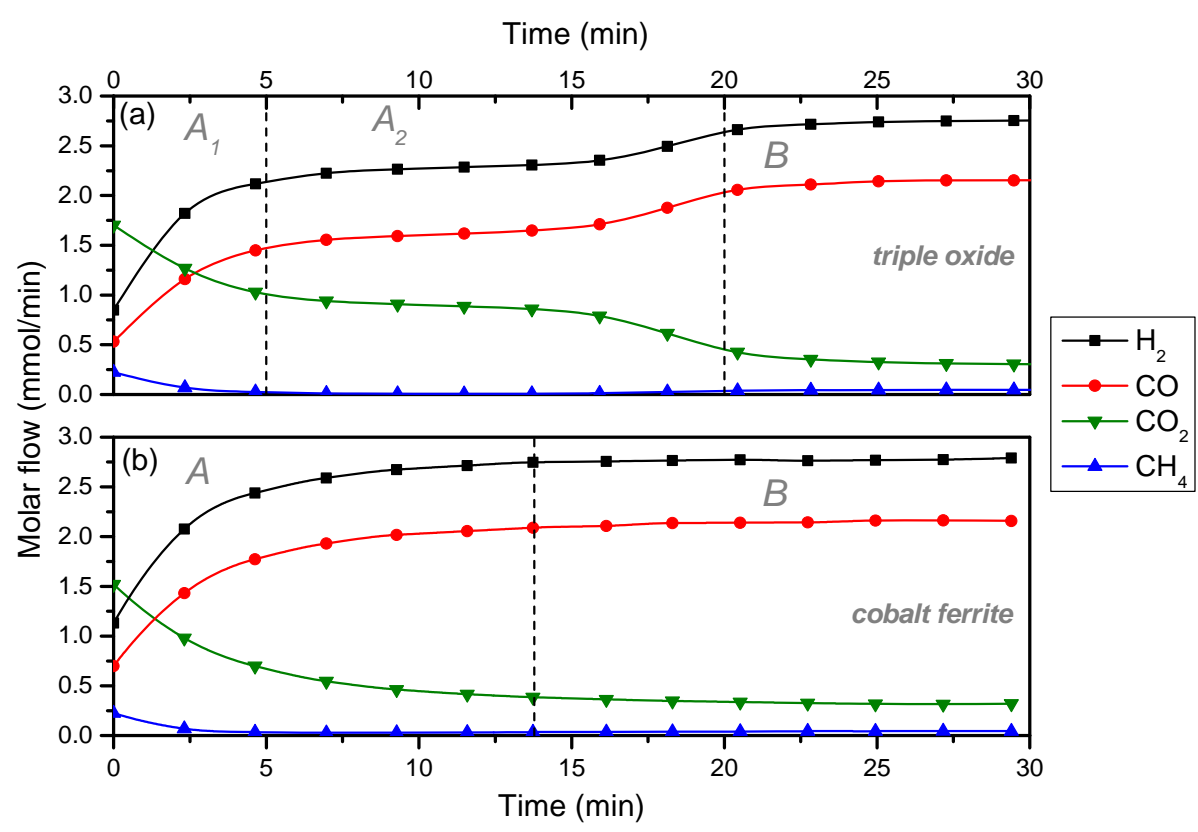

Fig. 1 - Molar flows at the exit of a fixed bed reactor along reduction stage for (a) triple oxide and (b) cobalt ferrite, co-feeding $5 \mathrm{v} \%$ of steam in the feedstock. $\left(T=700{ }^{\circ} \mathrm{C}\right)$.

Along sub-step $\mathrm{A}_{2}$, magnetite is reduced to metallic iron ((r.14) and (r.15)). In this period, molar flows of products are practically constant due to the strong influence of the equilibrium between magnetite and metallic iron. This behaviour has been described yet previously in more depth [10].

On the other hand, when cobalt ferrite is employed as oxygen carrier (Fig. 1b), the reduction of the solid occurs along a single step A, where it is taking place the reduction of nickel oxide and cobalt ferrite ( $r .7$ through r.10). As consequence of this reduction, emerging nickel and cobalt, this last in a minor extent, catalyze reactions (r.3) and (r.4), contributing to the formation of $\mathrm{H}_{2}$ and $\mathrm{CO}$, which in turn are consumed by the ferrite up to its complete reduction. Finally, as was described for triple oxide, step B shows the equilibrium between gaseous species once the cobalt ferrite has been completely depleted.

Oxidation stages were performed following the previous reduction in the conditions described in the experimental chapter of this work. Reactions involved in these stages are well described by the reverse (r.14) reaction. Hematite $\left(\mathrm{Fe}_{2} \mathrm{O}_{3}\right)$ is not favoured by thermodynamics at the operating conditions in which experiments were carried out.

\section{Effect of co-feeding biogas and steam in the reduction stage}

\section{Cobalt ferrite}

Fig. $2 \mathrm{a}$ and $\mathrm{b}$ shows the evolution along the reduction stage of the molar flows of $\mathrm{H}_{2}, \mathrm{CH}_{4}$ and the $\mathrm{CO}$ ratio (eq. (1)) at the exit of reactor.

CO ratio $=\frac{\text { molar flow of } \mathrm{CO}}{\text { molar flow of } \mathrm{CO}+\text { molar flow of } \mathrm{CO}_{2}}$

$\mathrm{CO}$ ratio (eq. (1)) reflects the relation between reducing carbonaceous compound $(\mathrm{CO})$ and oxidizing one $\left(\mathrm{CO}_{2}\right)$. As it can be seen in Fig. 2a, the greater is the percentage of steam co-fed, the lower is the methane conversion (i.e. higher $\mathrm{CH}_{4}$ flow) at the exit of reactor along the first minutes. This fact might be attributed to the significant inhibiting behaviour of steam towards reduction of nickel oxide present in the catalyst: a low proportion of metallic nickel implies that a significant proportion of reactants $\left(\mathrm{CH}_{4}\right.$ and $\left.\mathrm{CO}_{2}\right)$ present in the feed will not be transformed in reducing species $\left(\mathrm{H}_{2}\right.$ and $\mathrm{CO}$ ). Reduction of $\mathrm{NiO}$ will progress along time increasing the amount of metallic nickel, catalyzing MDR and consuming $\mathrm{CH}_{4}$ and $\mathrm{CO}_{2}$ (not shown). On the other hand, in Fig. $2 \mathrm{~b}$ it is possible to observe, as predicted by thermodynamics, that $\mathrm{CO}$ ratio (eq. (1)) decreases as higher is the percentage of steam co-fed.

\section{Triple oxide}

Like Fig. 2, Fig. 3 shows the behaviour along the reduction stage for triple oxide. As in the previous case, there is an increment in the amount of methane present in the first minutes as the proportion of steam in the feed is increased. Unlike cobalt ferrites, the higher amount of unreacted methane does not result in a pronounced delay of the reduction of hematite to magnetite since the mixture supplied (synthetic biogas + steam) has sufficient reducing capacity to allow such reduction (Fig. 3a). However, the loss of reducing capacity of the feed as the percentage of steam increases (Fig. 3b) inhibits at some extent the reduction of magnetite to iron, increasing the period required to completely reduce the solid.

\section{Effect of repeated redox cycles on the reduction stage}

Fig. 4 shows the evolution of $\mathrm{H}_{2}, \mathrm{CH}_{4}$, and $\mathrm{CO}$ ratio (eq. (1)) throughout the first three reduction stages, co-feeding $10 \mathrm{v} \%$ of steam jointly with biogas for both oxygen carriers: triple 


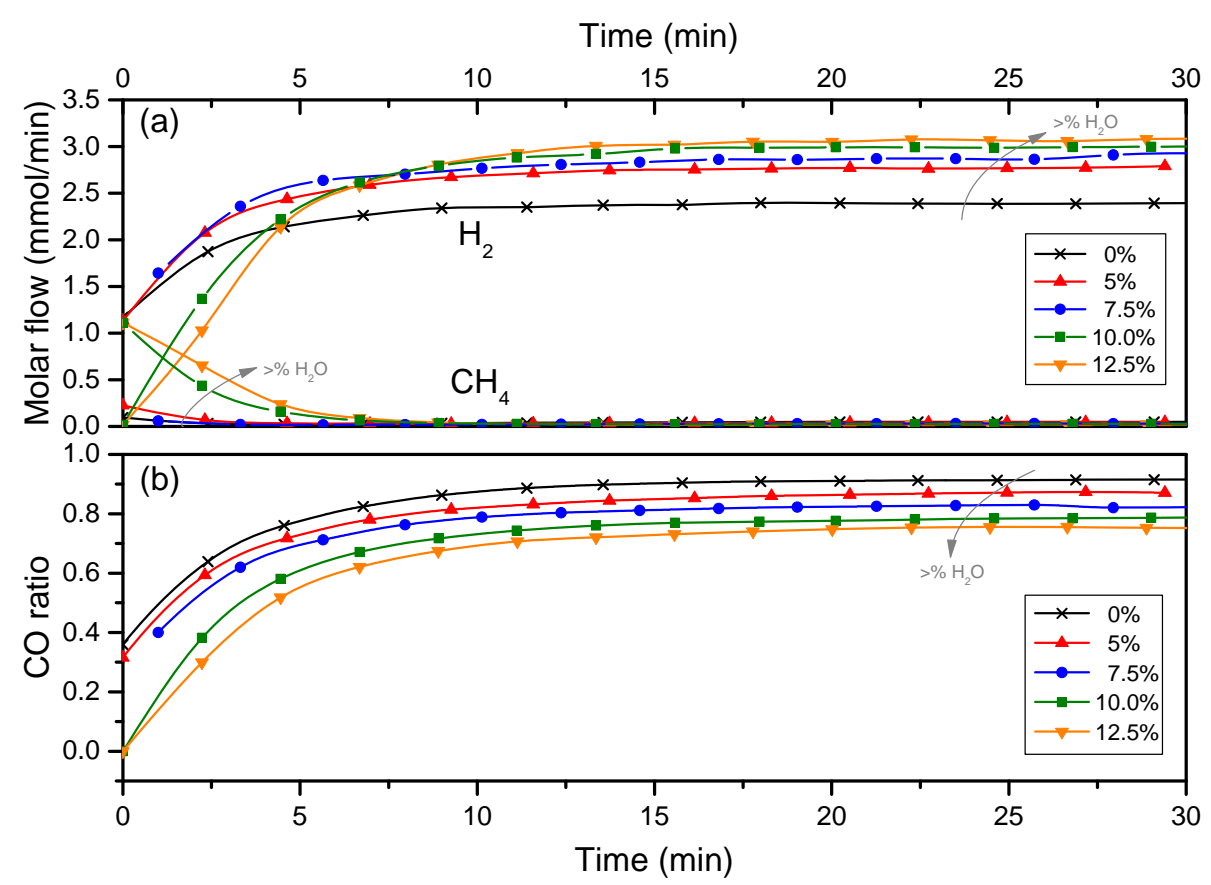

Fig. 2 - (a) Evolution of $\mathrm{H}_{2}$ and $\mathrm{CH}_{4}$ molar flows at the exit of reactor, and (b) $\mathrm{CO}$ ratio (eq. (1)), along reduction stage of cobalt ferrites, co-feeding different percentages of steam (5-12.5 v\%) with the equimolar mixture of $\mathrm{CH}_{4}$ and $\mathrm{CO}_{2}$.

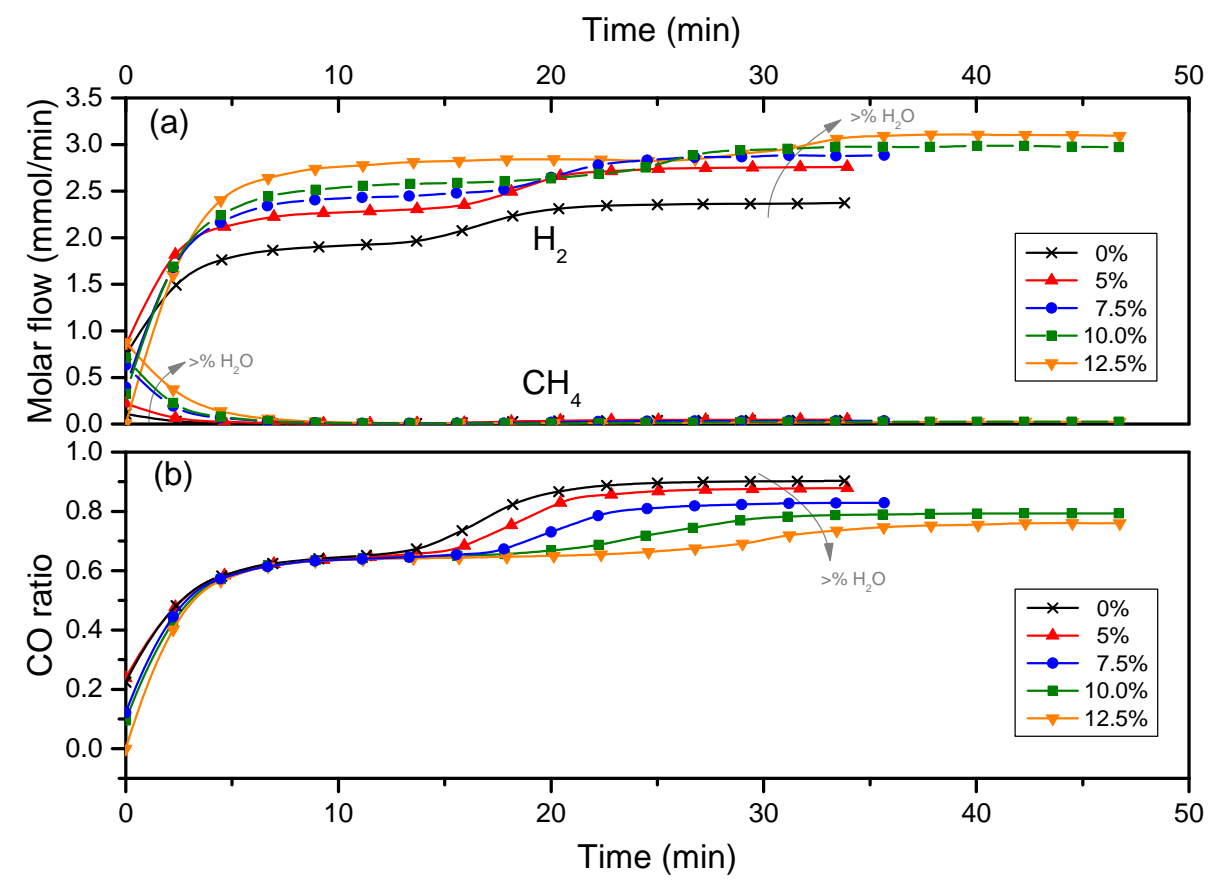

Fig. 3 - (a) Evolution of $\mathrm{H}_{2}$ and $\mathrm{CH}_{4}$ molar flows at the exit of reactor, and (b) $\mathrm{CO}$ ratio (eq. (1)), along reduction stage of triple oxide, co-feeding different percentages of steam (5-12.5 v\%) with the equimolar mixture of $\mathrm{CH}_{4}$ and $\mathrm{CO}_{2}$.

oxide (Fig. 4a) and cobalt ferrite (Fig. 4b). It is observed that the presence of unreacted methane in the first moments of reduction, pointed out in Figs. $2 \mathrm{a}$ and $3 \mathrm{a}$, only occurs in the first cycle regardless of the solid used.

In sight of this phenomenon, it is suggested as hypothesis that at the beginning of the first cycle, and only along this one, the catalytically active species for reforming reactions (i.e. metallic Ni) is not present "as is" but in its oxidized state (NiO) (note that catalyst particles consist of nickel aluminate with $10 \mathrm{wt} \%$ of $\mathrm{NiO}$ excess above the stoichiometric proportion). Along the first cycle, $\mathrm{NiO}$ is reduced by the feed (i.e. $\mathrm{CH}_{4}$ present on it), which retains a significant reducing capacity, allowing that $\mathrm{CH}_{4}$ remains unreacted along time, due to the lack of metallic nickel in a significant amount. This fact has 


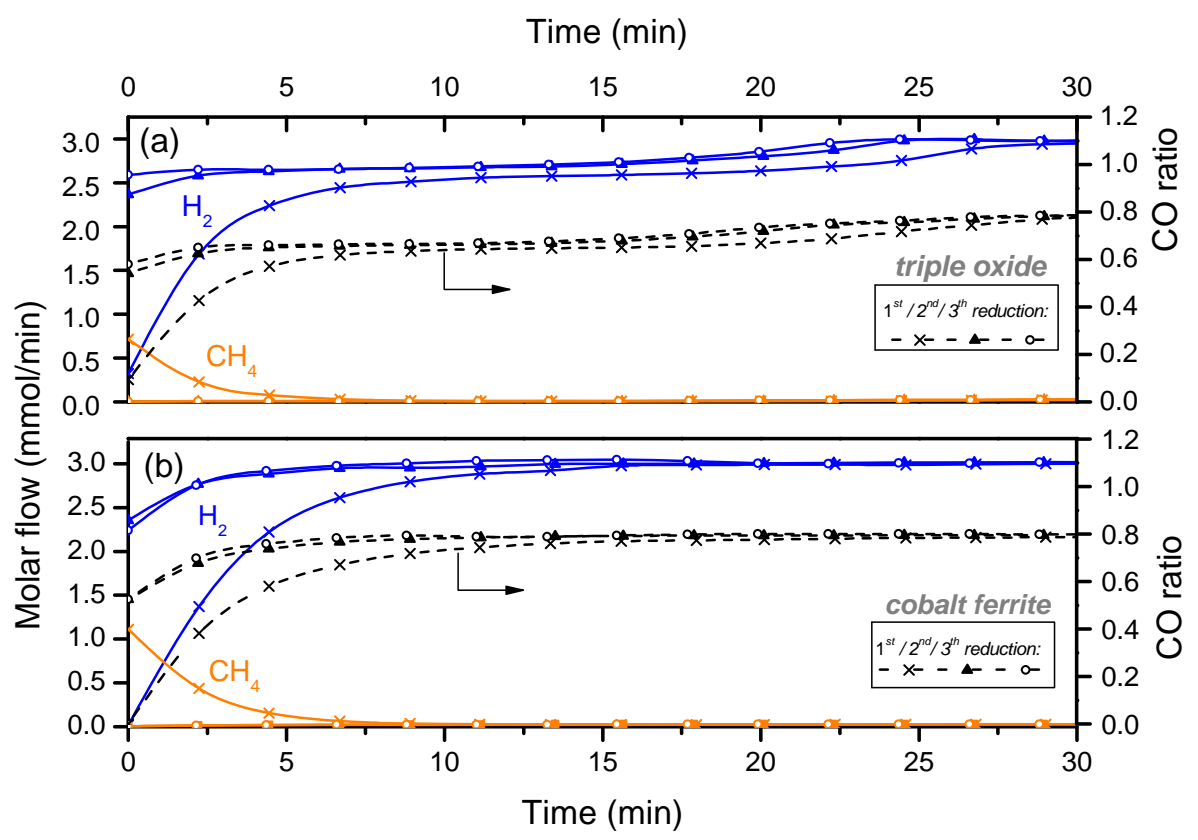

Fig. 4 - (a) Evolution of $\mathrm{H}_{2}$ and $\mathrm{CH}_{4}$ molar flows (left $\mathrm{Y}$ axis) and $\mathrm{CO}$ ratio (eq. (1)) (right $\mathrm{Y}$ axis) along three consecutive reduction stages of (a) triple oxide and (b) cobalt ferrite, supplying a $10 \mathrm{v} \%$ of steam in the feed.

been observed only along the first cycle (i.e. first reduction); since at the beginning of the subsequent reductions most nickel is already in its metallic form, the bed has sufficient catalytic capacity to allow the almost complete conversion of methane present in the feed. Moreover, the time required to reduce the solid decreases significantly from the first to the second and third cycles, being the difference between the last two cycles practically negligible regardless of the oxygen carrier used. This behaviour has already been described in previous works $[8,10]$, being attributed to the loss of reducible mass of solid resulting from the partial reoxidation on the solid in previous cycles. The difference in behaviour between first and following cycles can be explained by the greater amount of $\mathrm{H}_{2}$ and $\mathrm{CO}$ produced from the very beginning when nickel is present along the first minutes of reduction in the second and third cycles (i.e. reductions) versus the inducting period needed to reduce $\mathrm{NiO}$ to metallic nickel characteristic of the first cycle.

\section{Analysis of coke deposition in the reduction stage}

Once the effect of co-feeding steam to the reduction stage has been analyzed, in this section, it is going to be estimated the amount of coke deposited on the bed along reduction stages. It must be noted that in all cases, where a percentage of steam greater than $3 \mathrm{v} \%$ was fed, the overpressure of the system along cycles kept constant, allowing thus the correct alternation of reduction and oxidations stages in an uninterrupted way.

The estimation of coke deposition has been performed by calculating the elemental carbon balance: all carbonaceous species apart from coke, which is presumably deposited on the bed, can be quantified by gas chromatography. Fig. 5 a shows the evolution of the carbon balance along the first stage of reduction of triple oxide for feeds with different proportions of steam. Results for cobalt ferrite are not plotted due to its analogous behaviour. As can be appreciated, increasing the proportion of steam, the carbon unbalance and consequently the deposition of carbon, is considerably minimized. From $5 \mathrm{v}$ $\%$ on of steam co-feeding, the carbon unbalance takes values around $0.5 \mathrm{mg} / \mathrm{min}$ regardless of the amount of steam fed. This value represents roughly $1 \%$ of carbon unbalance, and can be mainly attributed to the systemic error of the experimental system used (including sampling and analysis by gas chromatography). On the other side, Fig. 5b shows the amount of coke deposited per $100 \mathrm{~g}$ of biogas fed, being lower in case of using cobalt ferrites. This difference can be attributed to the greater proportion of iron present in triple oxide which would favour a higher deposition of carbonaceous species [22].

\section{Influence of steam co-feeding with biogas: Oxidation stage}

Fig. 6 shows the hydrogen produced throughout the oxidation stages carried out at $500{ }^{\circ} \mathrm{C}$ after the reduction stages previously described. As it can be seen, as lower is the proportion of steam supplied in the previous reduction stage, higher is the amount of hydrogen obtained in the subsequent oxidation. That occurs because the higher the proportion of steam supplied, the more restricted is the reduction of the solid, and consequently the metal oxide is reduced in a lower extent (i.e. only partially).

If the production of hydrogen is analyzed along three consecutive cycles, it can also be observed a drop between cycles in case of using triple oxide as oxygen carrier. Cobalt ferrite, instead, despite its low oxidation rate [7], produces less hydrogen, but without an appreciable deactivation along the redox cycles. It is important to highlight that in all cycles performed, the high purity of the hydrogen produced is guaranteed ( $\leq 50 \mathrm{ppm} \mathrm{CO})$. 

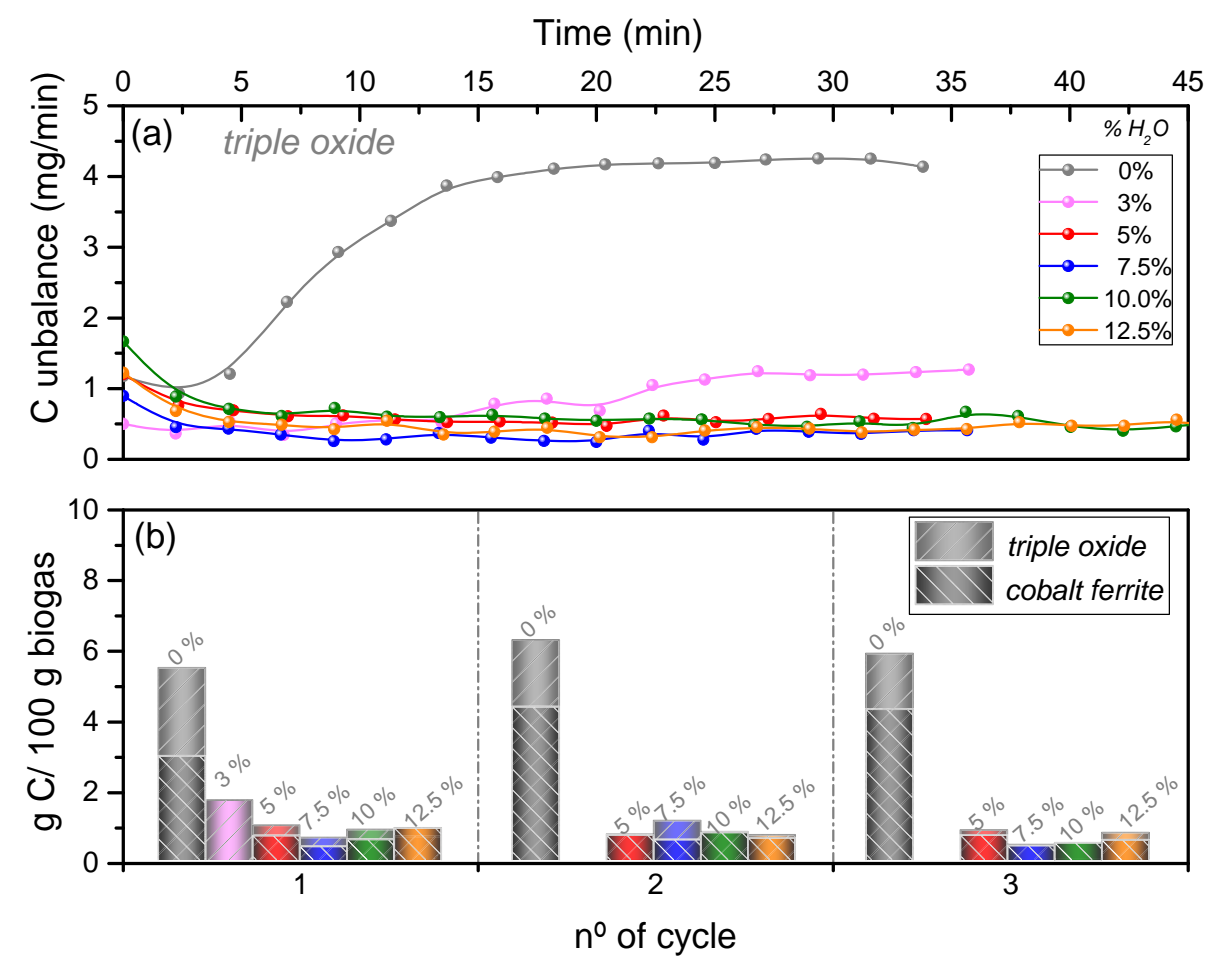

Fig. 5 - (a) Carbon unbalance along time in the reduction stage of triple oxide supplying different percentages of steam (5-12.5 v\%) in the feed. (b) Mass of carbon deposited in the bed/100 $\mathrm{g}$ of biogas supplied for several percentages of steam and up to three consecutive cycles using triple oxide and cobalt ferrite as oxygen carriers.

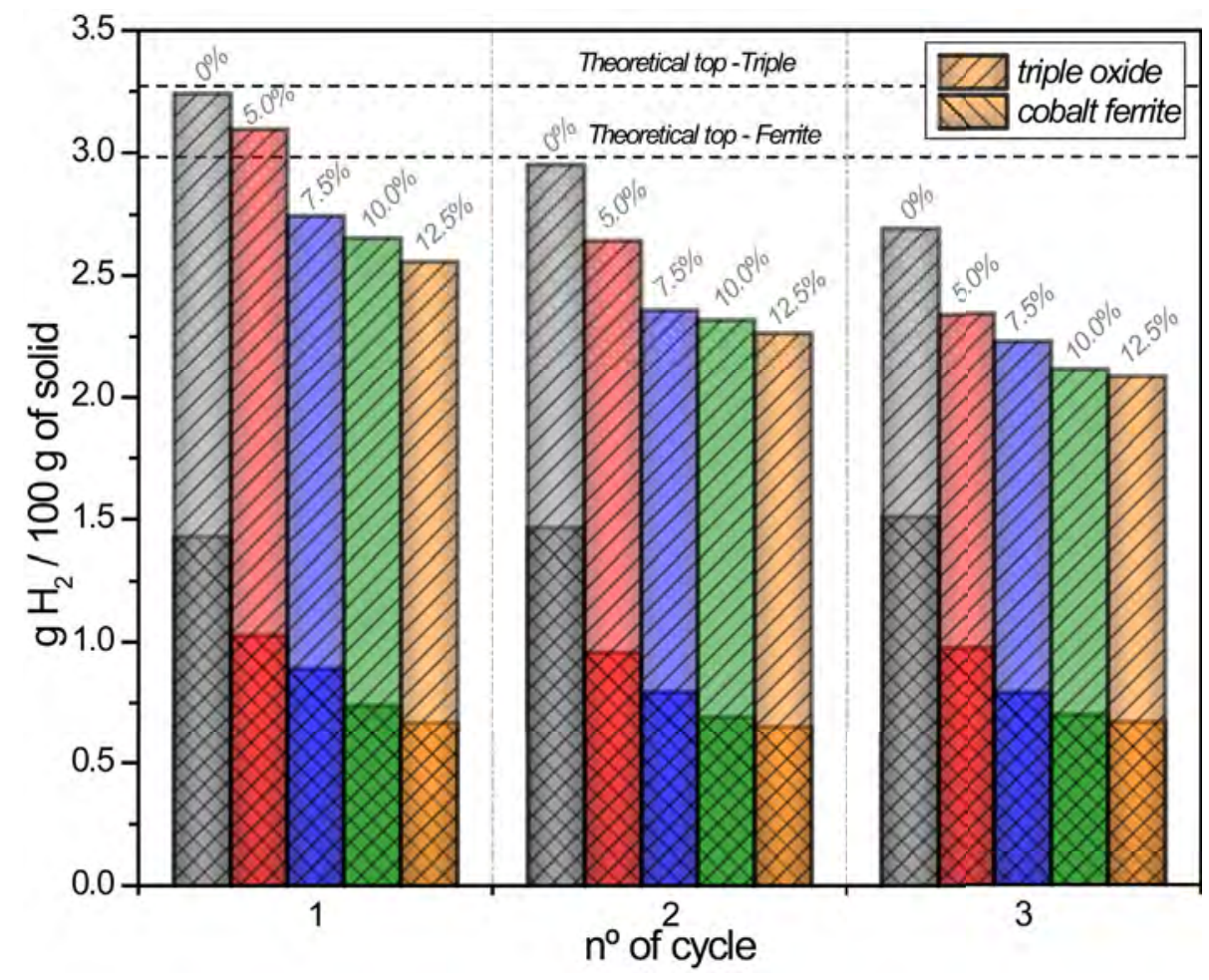

Fig. $6-\mathrm{g} \mathrm{H}_{2}$ produced/100 g of solid along 3 consecutive oxidation stages for triple oxide and cobalt ferrite, co-feeding different percentages of steam (5-12.5 v\%) along the previous reduction stages. 
Based on the results obtained, the optimal composition of steam to co-feed in reductions should be around $5 \mathrm{v} \%$, because under these conditions it is possible to minimize or even completely avoid the coke deposited on the bed as well as maximizing the hydrogen produced along the subsequent oxidations.

\section{Stability tests of oxygen carriers}

In redox cycles without steam co-feeding, the oxidation temperature was limited to $500{ }^{\circ} \mathrm{C}$ to avoid the eventual gasification by steam of the coke deposited along previous reduction stages [7]. After applying the solution proposed in this study, the carbon deposition has been minimized, opening the possibility of increasing the oxidation temperature. This would allow, a priori, the use of the same temperature as in the previous stage of reduction $\left(700^{\circ} \mathrm{C}\right)$ eliminating cooling and/or heating periods between stages and therefore reducing the number of reactors necessary to carry out the process in a continuous manner. To check the stability of each of the oxygen carriers studied, up to 13 consecutive redox cycles were performed co-feeding $5 \mathrm{v} \%$ of steam along reductions, using temperatures of $500^{\circ} \mathrm{C}$ and $700^{\circ} \mathrm{C}$ in the subsequent oxidation stages.

Fig. 7 shows the mass of hydrogen produced along the oxidation step per $100 \mathrm{~g}$ of hydrogen present in biogas fed during the previous reduction (Fig. 7a) and the mass of hydrogen produced per $100 \mathrm{~g}$ of oxygen carrier (Fig. 7b). No $\mathrm{CO}_{\mathrm{x}}$ was detected in any of the cycles, despite of using up to $700{ }^{\circ} \mathrm{C}$ as oxidation temperature. This fact supports the hypothesis that the carbon unbalance associated with the production of coke (Fig. 5a) is related to experimental error instead of a real deposition of carbonaceous residue.
On the other side, a remarkable increase of the hydrogen production is observed with cobalt ferrite in case of oxidations at $700{ }^{\circ} \mathrm{C}$ respecting its counterpart at $500^{\circ} \mathrm{C}$. This shift can be attributed to the higher oxidation rate in accordance with the higher process temperature, increasing therefore the amount of reducible oxide along cycles. Moreover, there are no appreciable signs of activity loss in the solid due to sintering phenomena [23-25], concluding that the results obtained with this material are very promising.

Triple oxide instead, exhibits a progressive fall in the production of hydrogen along redox cycles due to sinterization of the oxide (Fig. 7b). This reduction in the amount of $\mathrm{H}_{2}$ produced along oxidations is especially intense in cycles performed with an oxidation temperature of $500{ }^{\circ} \mathrm{C}$ evidencing a progressive loss of activity in the bed. In case of using $700^{\circ} \mathrm{C}$, it is possible to obtain despite deactivation, hydrogen yields higher than those obtained with cobalt ferrite. The reason is that employing higher temperature along oxidation stages, the time necessary to reoxidize the triple oxide is shortened because the increase in kinetics prevails over the sintering process. This last is also responsible of the progressive increase of time needed to reduce the solid (not shown) and a gradual increment in the reactor overpressure. Since there is no evidence of coke deposition, the conclusion is that an eventual clogging of reactor would be caused by partial melting and collapse of solid particles making the process unpracticable at these temperatures for a sustained number of cycles.

\section{Comparison of empirical results with literature}

The hydrogen yields (i.e. $\mathrm{g} \mathrm{H}_{2}$ produced per $100 \mathrm{~g}$ of $\mathrm{H}_{2}$ present in biogas -as molecular constituent of $\mathrm{CH}_{4}-$ ) obtained using both solids tested in this work have been compared with data

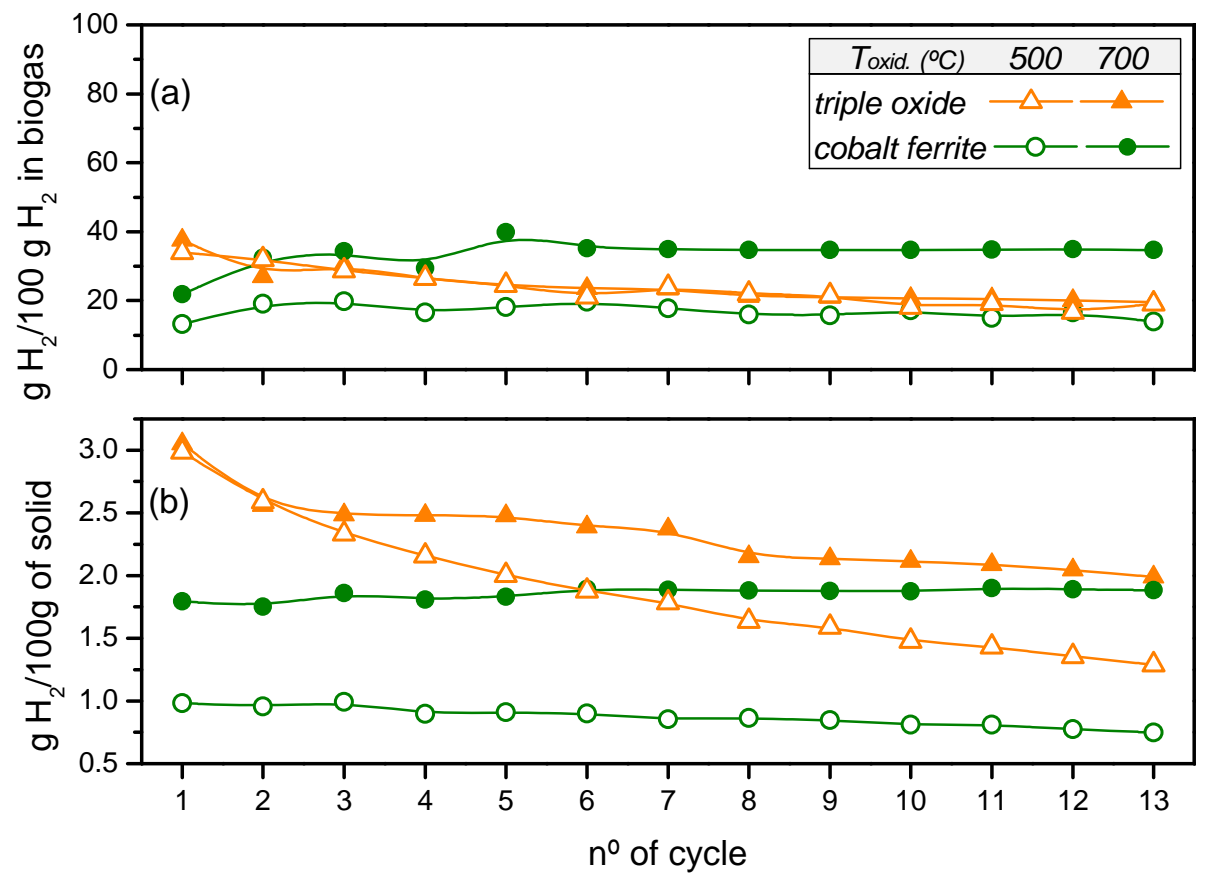

Fig. 7 - Yields of MDR + SIP as (a) $\mathrm{g} \mathrm{H}_{2}$ produced/100 $\mathrm{g}$ of $\mathrm{H}_{2}$ in biogas and (b) $\mathrm{g}_{2}$ produced/100 $\mathrm{g}$ of solid along up to 13 consecutive cycles for triple oxide and cobalt ferrite at 500 and $700{ }^{\circ} \mathrm{C}$, supplying $5 \mathrm{v} \%$ of steam in the reduction stage $\left(\mathrm{CH}_{4}+\mathrm{CO}_{2}\right.$ equimolar mixtures accounting for $\left.25 \mathrm{v} \%\right)$. 


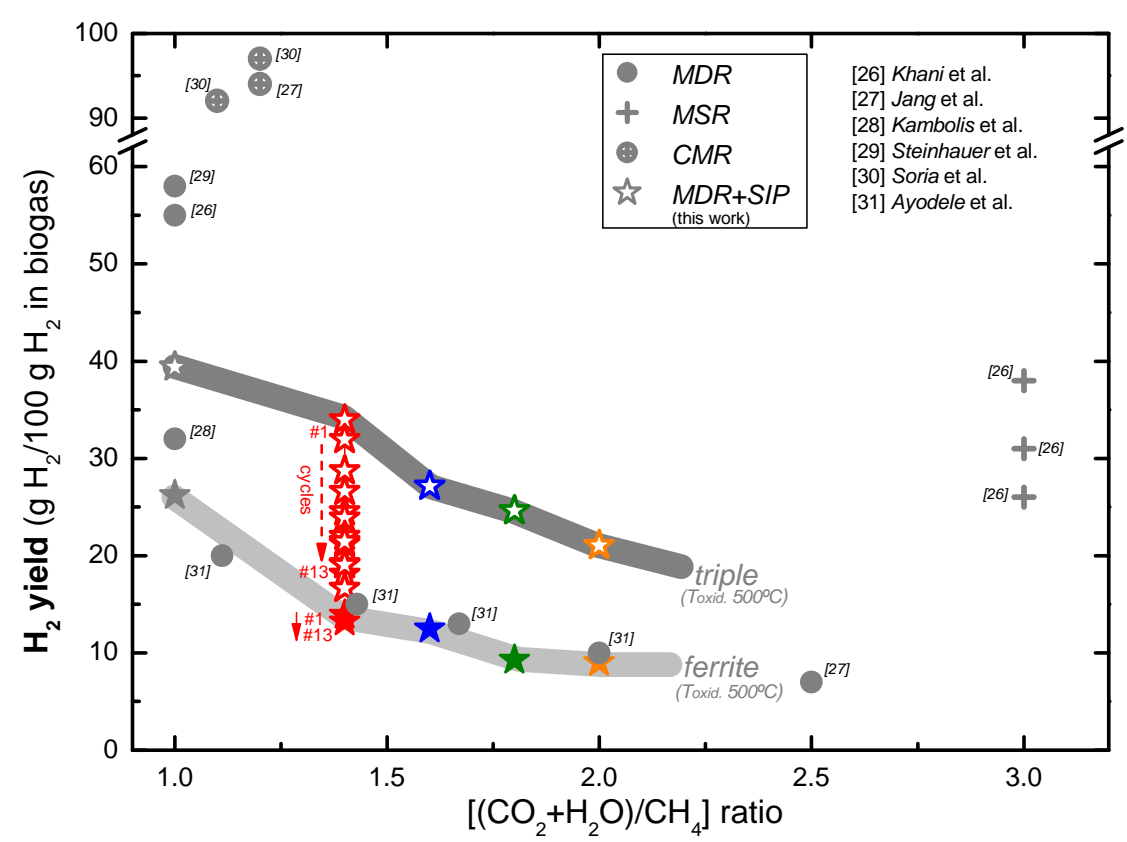

Fig. $8-\mathrm{g} \mathrm{H}_{2}$ produced/100 $\mathrm{g}$ of $\mathrm{H}_{2}$ contained in biogas using cobalt ferrite (solid stars) and triple oxide (hollow stars), depending on the composition of the feed along reductions, compared with literature data [26-31]. The colour code is the same as in Figs. 2, 3, 5 and 6. (For interpretation of the references to color/colour in this figure legend, the reader is referred to the Web version of this article.)

published in literature. All processes considered for comparison (MDR, MSR or Combined Methane Reforming -CMR-) were carried out at temperatures around $700{ }^{\circ} \mathrm{C}$, but using different catalysts based on $\mathrm{Ni}, \mathrm{Ni}-\mathrm{Pd}, \mathrm{Ni}-\mathrm{MgO}, \mathrm{Ru}, \mathrm{Co}$ and $\mathrm{Ni}-\mathrm{Ru}-\mathrm{Pt}$ [26-31]. Fig. 8 shows, for the sake of comparison, the results cited in literature or measured in our laboratory vs. $\left[\left(\mathrm{CO}_{2}+\mathrm{H}_{2} \mathrm{O}\right) / \mathrm{CH}_{4}\right]$ flow ratio in the feed supplied. Star symbols represent different yields obtained in this work in case of, from left to right, $0 \mathrm{v} \%, 5 \mathrm{v} \%, 7.5 \mathrm{v} \%, 10 \mathrm{v} \%$ and $12.5 \mathrm{v} \%$ of steam co-feeding for triple oxide (hollow stars) and cobalt ferrite (solid stars). In case of $5 \mathrm{v} \%\left(\left[\left(\mathrm{CO}_{2}+\mathrm{H}_{2} \mathrm{O}\right) / \mathrm{CH}_{4}\right]\right.$ ratio $\left.=1.4\right)$, a succession of stars shows the $\mathrm{H}_{2}$ yield evolution along cycles (from the first one labelled as \#1 through the last one \#13) carried out with triple oxide using $700{ }^{\circ} \mathrm{C}$ for reductions and $500{ }^{\circ} \mathrm{C}$ for oxidations. Opposite trend exhibits the results obtained with cobalt ferrites which increase their yields along cycles (see Fig. 7a).

In general, the yields obtained in this work are in the same order of those reported for MDR when cobalt ferrite is the oxygen carrier. Actually, the hydrogen yields are similar to those reported by Ayodele et al. [31]. Higher yields were obtained when triple oxide was used as oxygen carrier for all proportions of steam co-feeding tested. However, as it can be seen in Fig. 8, the evolution of these results along several cycles leads to a similar performance than when ferrite has been used. On the other side, for processes involving MSR [26] or CMR $[27,30]$, results published in literature are clearly better. However, it is important to highlight that hydrogen obtained in this work by MDR + SIP has high purity ( $\leq 50 \mathrm{ppm}$ CO), unlike that obtained by MSR or CMR described in literature that should be purified in a subsequent stage.

\section{Conclusions}

In present work it has been analyzed the effect of co-feeding small proportions of steam jointly with a simulated desulphurized biogas (equimolar mixture of $\mathrm{CH}_{4}$ and $\mathrm{CO}_{2}$ accounting for $25 \mathrm{v} \%$ of the total feed) supplied as reductant for SIP. Regardless of the oxygen carrier employed, supplying $5 \mathrm{v} \%$ of steam is enough to avoid deposition of coke along reductions at $700{ }^{\circ} \mathrm{C}$, without affecting significantly the behaviour in reduction of the oxygen carrier tested, as well as the purity of the hydrogen obtained along subsequent oxidations ([CO] $\leq 50 \mathrm{ppm})$. The use of a higher percentage of steam in the feed provokes a partial inhibition of the in-situ activation of the nickel oxide employed as catalyst precursor $\left(\mathrm{NiAl}_{2} \mathrm{O}_{4}\right.$ with $10 \mathrm{wt} \% \mathrm{NiO}$ in excess above the stoichiometric), increasing thus the time requited for reduction of the bed of solids. This problem though, is negligible since it only occurs along the first reduction. Elimination of coke deposition in reductions has allowed the isothermal operation of SIP at $700{ }^{\circ} \mathrm{C}$ using cobalt ferrite as oxygen carrier, and making possible eliminating the need of heating and/or cooling steps between reductions and oxidations. Finally, results obtained with $\mathrm{MDR}+\mathrm{SIP}$ are comparable to those found in literature for MDR, but not for SMR or CMR; needless to say, that hydrogen obtained by MDR + SIP is a high purity product and that a 
subsequent purification stage (e.g. membranes, PSA, ...) would be required for hydrogen produced by SMR or CMR.

\section{Acknowledgements}

Financial support for this work has been provided by the Spanish Ministerio de Economía y Competitividad (MINECO), through projects ENE2013-44350-R and CTQ2016-77277-R. J. Lachén also thanks the same institution for the grant BES2014-067984. Financial aid for the maintenance of the consolidated research group CREG has been provided by the Fondo Social Europeo (FSE) through the Gobierno de Aragón (Aragón, Spain).

\section{R E F E R E N C E S}

[1] Moliner R, Lázaro M, Suelves I. Analysis of the strategies for bridging the gap towards the hydrogen economy. Int $\mathrm{J}$ Hydrogen Energy 2016;41:19500-8. https://doi.org/10.1016/ j.ijhydene.2016.06.202.

[2] Hosseini SE, Wahid MA. Hydrogen production from renewable and sustainable energy resources: promising green energy Carrier for clean development. Renew Sustain Energy Rev 2016;57:850-66. https://doi.org/10.1016/ j.rser.2015.12.112.

[3] Porter RTJ, Fairweather M, Kolster C, Mac Dowell N, Shah N, Woolley RM. Cost and performance of some carbon capture technology options for producing different quality $\mathrm{CO}_{2}$ product streams. Int J Greenh Gas Control 2017;57:185-95. https://doi.org/10.1016/j.ijggc.2016.11.020.

[4] Nandy A, Loha C, Gu S, Sarkar P, Karmakar MK, Chatterjee PK. Present status and overview of chemical looping combustion technology. Renew Sustain Energy Rev 2016;59:597-619. https://doi.org/10.1016/J.RSER.2016.01.003.

[5] Liguori R, Faraco V. Biological processes for advancing lignocellulosic waste biorefinery by advocating circular economy. Bioresour Technol 2016;215:13-20. https://doi.org/ 10.1016/j.biortech.2016.04.054.

[6] Messerschmitt A. Process of producing hydrogen. 1910. U.S. Patent No. 971, 206.

[7] Lachén J, Durán P, Peña JA, Herguido J. High purity hydrogen from coupled dry reforming and steam iron process with cobalt ferrites as oxygen carrier: process improvement with the addition of $\mathrm{NiAl}_{2} \mathrm{O}_{4}$ catalyst. Catal Today 2017;296:163-9. https://doi.org/10.1016/j.cattod.2017.04.046.

[8] Lachén J, Plou J, Durán P, Herguido J, Peña JA. Iron oxide ores as carriers for the production of high purity hydrogen from biogas by steam-iron process. Int J Hydrogen Energy 2017;42:13607-16. https://doi.org/10.1016/j.ijhydene.2016. 11.152.

[9] Plou J, Durán P, Herguido J, Peña JA. Hydrogen from synthetic biogas by catalyzed MDR and SIP: screening of catalyst and iron oxide mixtures. Fuel 2015;140:470-6. https://doi.org/ 10.1016/j.fuel.2014.09.116.

[10] Herrer M, Plou J, Durán P, Herguido J, Peña JA. Hydrogen from synthetic biogas via SIP using $\mathrm{NiAl}_{2} \mathrm{O}_{4}$ catalyst: reduction stage. Int J Hydrogen Energy 2015;40:5244-50. https://doi.org/ 10.1016/j.ijhydene.2015.01.063.

[11] Campo R, Durán P, Plou J, Herguido J, Peña JA. Combined production and purification of hydrogen from methanol using steam iron process in fixed bed reactor. J Power
Sources 2013;242:520-6. https://doi.org/10.1016/j.jpowsour. 2013.05.146.

[12] Hormilleja E, Durán P, Plou J, Herguido J, Peña JA. Hydrogen from ethanol by steam iron process in fixed bed reactor. Int $J$ Hydrogen Energy 2014;39:5267-73. https://doi.org/10.1016/ j.ijhydene.2014.01.002.

[13] Plou J, Lachén J, Durán P, Herguido J, Peña JA. Pure hydrogen from lighter fractions of bio-oil by steam-iron process: effect of composition of bio-oil, temperature and number of cycles. Fuel 2017;203:452-9. https://doi.org/10.1016/j.fuel.2017. 04.127.

[14] Son IH, Lee SJ, Soon A, Roh H-S, Lee H. Steam treatment on $\mathrm{Ni} / \gamma-\mathrm{Al}_{2} \mathrm{O}_{3}$ for enhanced carbon resistance in combined steam and carbon dioxide reforming of methane. Appl Catal B Environ 2013;134-135:103-9. https://doi.org/10.1016/ j.apcatb.2013.01.001.

[15] Demidov DV, Mishin IV, Mikhailov MN. Gibbs free energy minimization as a way to optimize the combined steam and carbon dioxide reforming of methane. Int J Hydrogen Energy 2011;36:5941-50. https://doi.org/10.1016/j.ijhydene.2011. 02.053.

[16] Danilova MM, Fedorova ZA, Zaikovskii VI, Porsin AV, Kirillov VA, Krieger TA. Porous nickel-based catalysts for combined steam and carbon dioxide reforming of methane. Appl Catal B Environ 2014;147:858-63. https://doi.org/ 10.1016/j.apcatb.2013.10.005.

[17] Karemore AL, Vaidya PD, Sinha R, Chugh P. On the dry and mixed reforming of methane over $\mathrm{Ni} / \mathrm{Al}_{2} \mathrm{O}_{3}$ - influence of reaction variables on syngas production. Int $\mathrm{J}$ Hydrogen Energy 2016;41:22963-75. https://doi.org/10.1016/ j.ijhydene.2016.09.038.

[18] Kirchnerova J, Alifanti M, Delmon B. Evidence of phase cooperation in the $\left(\mathrm{LaCoO}_{3}-\mathrm{CeO}_{2}-\mathrm{Co}_{3} \mathrm{O}_{4}\right)$ catalytic system in relation to activity in methane combustion. Appl Catal A Gen 2002;231:65-80. https://doi.org/10.1016/S0926-860X(01) 00903-6.

[19] Lázaro MJ, Echegoyen Y, Alegre C, Suelves I, Moliner R, Palacios $\mathrm{JM}^{\mathrm{TiO}} \mathrm{TiO}_{2}$ as textural promoter on high loaded $\mathrm{Ni}$ catalysts for methane decomposition. Int J Hydrogen Energy 2008;33:3320-9. https://doi.org/10.1016/j.ijhydene.2008. 03.050 .

[20] Al-Ubaid A, Wolf EE. Steam reforming of methane on reduced non-stoichiometric nickel aluminate catalysts. Appl Catal 1988;40:73-85. https://doi.org/10.1016/S0166-9834(00) 80427-3.

[21] Lachén J, Durán P, Menéndez M, Peña JA, Herguido J. Biogas to high purity hydrogen by methane dry reforming in TZFBR $+\mathrm{MB}$ and exhaustion by steam-iron process. Techno-economic assessment. Int J Hydrogen Energy 2018. https://doi.org/10.1016/j.ijhydene.2018.03.105.

[22] Ermakova MA, Ermakov DY, Chuvilin AL, Kuvshinov GG. Decomposition of methane over iron catalysts at the range of moderate temperatures: the influence of structure of the catalytic systems and the reaction conditions on the yield of carbon and morphology of carbon filaments. J Catal 2001;201:183-97. https://doi.org/10.1006/jcat.2001.3243.

[23] Fukase S, Suzuka T. Residual oil cracking with generation of hydrogen: deactivation of iron oxide catalyst in the steamiron reaction. Appl Catal A Gen 1993;100:1-17. https:// doi.org/10.1016/0926-860X(93)80111-3.

[24] Thaler M, Hacker V, Anilkumar M, Albering J, Besenhard JO, Schröttner $\mathrm{H}$, et al. Investigations of cycle behaviour of the contact mass in the RESC process for hydrogen production. Int J Hydrogen Energy 2006;31:2025-31. https://doi.org/ 10.1016/j.ijhydene.2006.01.009.

[25] Lorente E, Peña JA, Herguido J. Kinetic study of the redox process for separating and storing hydrogen: oxidation stage 
and ageing of solid. Int J Hydrogen Energy 2008;33:615-26. https://doi.org/10.1016/j.ijhydene.2007.09.026.

[26] Khani Y, Shariatinia Z, Bahadoran F. High catalytic activity and stability of $\mathrm{ZnLaAlO}_{4}$ supported $\mathrm{Ni}$, Pt and $\mathrm{Ru}$ nanocatalysts applied in the dry, steam and combined drysteam reforming of methane. Chem Eng J 2016;299:353-66. https://doi.org/10.1016/j.cej.2016.04.108.

[27] Jang W-J, Jeong D-W, Shim J-O, Kim H-M, Roh H-S, Son IH, et al. Combined steam and carbon dioxide reforming of methane and side reactions: thermodynamic equilibrium analysis and experimental application. Appl Energy 2016;173:80-91. https://doi.org/10.1016/j.apenergy.2016. 04.006 .

[28] Kambolis A, Matralis H, Trovarelli A, Papadopoulou C. Ni/ $\mathrm{CeO}_{2}-\mathrm{ZrO}_{2}$ catalysts for the dry reforming of methane. Appl Catal A Gen 2010;377:16-26. https://doi.org/10.1016/ j.apcata.2010.01.013.
[29] Steinhauer B, Kasireddy MR, Radnik J, Martin A.

Development of Ni-Pd bimetallic catalysts for the utilization of carbon dioxide and methane by dry reforming. Appl Catal A Gen 2009;366:333-41. https://doi.org/10.1016/j.apcata. 2009.07.021.

[30] Soria MA, Mateos-Pedrero C, Guerrero-Ruiz A, RodríguezRamos I. Thermodynamic and experimental study of combined dry and steam reforming of methane on $\mathrm{Ru} / \mathrm{ZrO}_{2}-$ $\mathrm{La}_{2} \mathrm{O}_{3}$ catalyst at low temperature. Int $\mathrm{J}$ Hydrogen Energy 2011;36:15212-20. https://doi.org/10.1016/j.ijhydene.2011. 08.117.

[31] Ayodele BV, Khan MR, Lam SS, Cheng CK. Production of COrich hydrogen from methane dry reforming over lanthaniasupported cobalt catalyst: kinetic and mechanistic studies. Int J Hydrogen Energy 2016;41:4603-15. https://doi.org/ 10.1016/j.ijhydene.2016.01.091. 